\title{
PROBABILITY DISTRIBUTION OF TIME DURATION OF MANUAL OPERATION IN THE PRODUCTION OF GLASS EYES
}

\section{${ }^{\mathrm{a}}$ VLADIMIR SOJKA, ${ }^{\mathrm{b}} \mathrm{PETR}$ LEPSIK}

Technical University of Liberec, Department of Design of Machine Elements and Mechanisms, Liberec, Czech Republic email: ${ }^{a}$ vladimir.sojka@tul.cz, ${ }^{b}$ petr.lepsik@tul.cz

This work was supported by the Student Grant Competition of the Technical University of Liberec under the project No. SGS-2020-5027 - Research of new approaches to process improvement. Abstract: When precise planning of capacities and times of production is needed, there must be precise data for calculation. Not all operations have to have a normal time duration distribution. Counting with average values or use values from guessed distribution can lead to mistakes in actual production planning. This article aims to determine time probability distributions to manual operations. Tests of goodness of fit are used to search for more suitable distributions. This approach is presented in a case study of glass eyes manufacturing. Results show that there can be differences between the estimated normal distribution and another more suitable one. By using tests of goodness of fit to define the correct distribution, more precise production and capacity planning results can be achieved.

Keywords: Capacity planning, Duration distribution, Manual processing, Production planning, Tests of goodness of fit

\section{Introduction}

Activities in production processes have not only a normal distribution of time duration. [1] This must be taken into account in calculations of production capacity and planning. Precise data about the time duration of operations is needed to have a more precise simulation model of the production system. Nowadays, there is more and more use of computer simulations of production processes and systems. Companies are trying to have highly accurate simulated systems. Simulations are then used for different kinds of improvement efforts. Production planning, layout design [2], or enhancement of productivity and efficiency of the process [3,4], these are just some of the possible applications of the production system simulation.

To get a relevant result from the simulation a valid data and its probabilities must be found. That is why a right probability distribution should be chosen. [5] The use of probability distributions to evaluate time can be seen, for example, in [6]

The aim of this paper is to define the probability distribution of the duration of production of one whole glass black eye in the glass eyes production process.

\section{Methods}

An operation that should be tested must be firstly sampled more measurements give a better result. For our purposes, 40 measurements are considered as enough data samples to describe the distribution well. A Few extra measurements should be made for the case when some of the measured samples must be eliminated.

\subsection{Goodness-of-Fit Tests}

A Shapiro-Wilk test could be used to test the normality of the distribution of the duration of sampled operation. The test is used for the determination of if the normal distribution models the data. The Shapiro-Wilk test tests a null hypothesis that sample $x_{1}$ to $x_{n}$ came from normal distribution. The test statistic is described by equation (1) below

$$
W=\frac{\left(\sum_{i=1}^{n} a_{i} x_{(i)}\right)^{2}}{\sum_{i=1}^{n}\left(x_{i}-\bar{x}\right)^{2}}
$$

Where $x_{(i)}$ is the $i$-th order statistic, $\bar{x}$ is the sample mean, coefficients $a_{i}$ can be given by equation (2)

$$
\left(a_{i}, \ldots, a_{n}\right)=\frac{m^{T} V^{-1}}{C}
$$

Where $C$ is a vector norm, vector $m$ is made of the expected values of the order statistics of independent and identically distributed random variables sampled from the standard normal distribution, $V$ is the covariance matrix of normal order statistics.

If the resulting P-value for an alpha level of 0.05 is less than 0.05 , the null hypothesis is rejected, so data are not normally distributed.

The Kolmogorov-Smirnov test is a test of the equality of probability distributions. It quantifies a distance between the empirical distribution function of the sample and the cumulative distribution of reference distribution. The test statistic is in equation (3) below.

$$
D_{n}=\sup _{-\infty<x<\infty}\left|F_{n}(x)-\Phi(x)\right|
$$

Where $F_{n}$ is the distribution function of the sample and $\Phi$ is the reference distribution.

For practical use, statistical software that makes all the calculations should be used.

\subsection{Probability distribution of time duration of glass eyes production}

The process where the determination of time duration distribution was applied is handmade manufacturing of glass eyes (Figure 1).

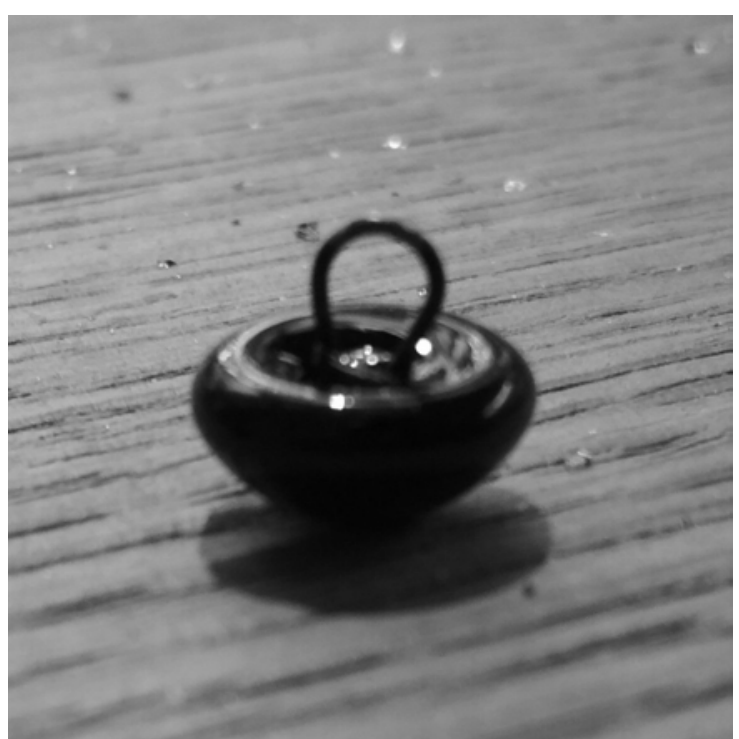

Figure 1: Produced black glass eye with wire loop

The process consists of several steps. Firstly, the wire loop is joined to the glass tube. Then the eye is formed on the loop in a fire and formed in a mold. Also, a diameter check is made at the same time. After that, eyes are slowly cooled down, and tubes are broken off. By using pliers, the remaining glass from the tube is cleaned off the wire loop. Eyes are then stored; packing depends on the type of customer's requirement. Several process phases can be seen in figure (Figure 2) bellow. 


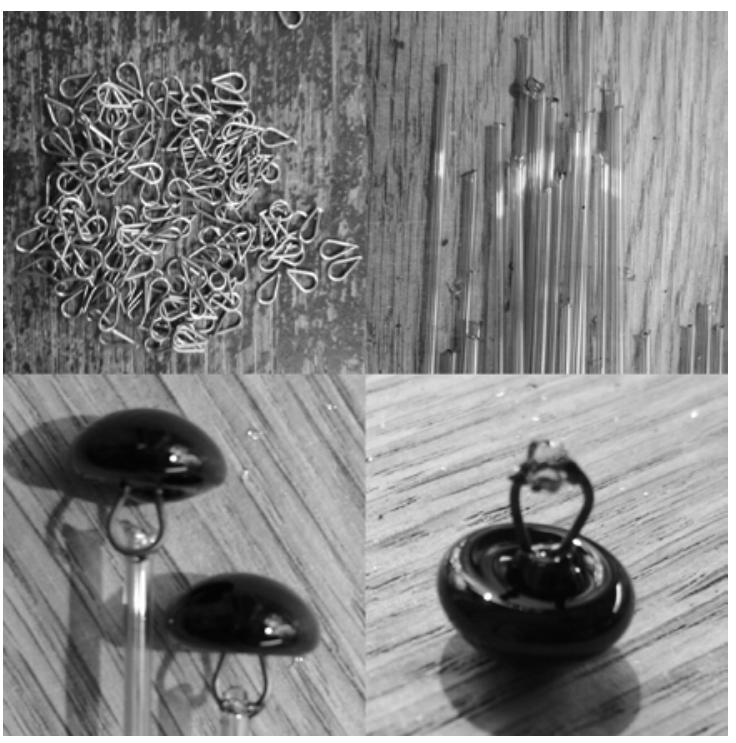

Figure 2: Process phases of glass eye production

For the whole glass eye production, a 40 measurement was done, a sample consists of values ranging from 53.17 to 86.08 seconds. Data were collected by direct measuring in production.

Tests of goodness of fit were used to determine which distribution fits best on the real sample of measured time durations of production operations. For practical use, Statgraphics 18 software was used.

\section{Results}

Firstly the measured data sample was analyzed, and test to normality was done.

Density Trace for whole eye duration [æc]

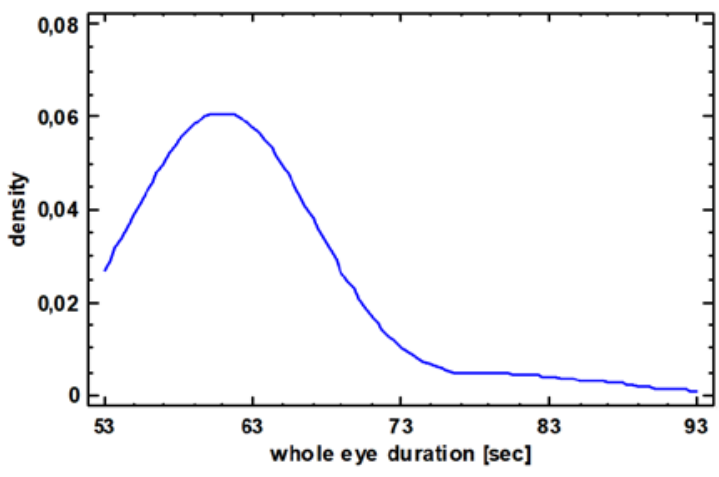

Figure 3: Density trace of whole eye duration

Figure (Figure 3) shows a density trace for whole eye duration. A density trace is essentially a smoothed histogram, which shows the shape of the distribution from which the sample comes. The trace is constructed by counting the number of observations within an interval of fixed width as it is moved along the x-axis, and weighting them in such a way as to give a smooth estimate of the underlying density function.

Tab. 1: Tests for Normality for whole eye duration

\begin{tabular}{|c|c|c|}
\hline Test & Statistic & P-Value \\
\hline Shapiro-Wilk W & 0.849568 & 0.0000878465 \\
\hline
\end{tabular}

Table (Tab. 1) shows the results of several tests run to determine whether whole eye duration can be adequately modeled by a normal distribution. The Shapiro-Wilk test is based upon comparing the quantiles of the fitted normal distribution to the quantiles of the data. Since the smallest P-value amongst the tests performed is less than 0.05 , we can reject the idea that whole eye duration comes from a normal distribution with $95 \%$ confidence.

For the measured data a four probability distribution were chosen to fit together with normal distribution for comparison.

Tab. 2: Fitted distributions

\begin{tabular}{|c|c|c|c|c|}
\hline $\begin{array}{c}\text { Larges } \\
\text { Extreme } \\
\text { Value }\end{array}$ & Logologistic & Lognormal & Weibull & Normal \\
\hline $\begin{array}{l}\text { Mode }= \\
59.6326\end{array}$ & $\begin{array}{c}\text { Median = } \\
61.4672\end{array}$ & $\begin{array}{l}\text { Mean = } \\
62.3265\end{array}$ & $\begin{array}{l}\text { Shape }= \\
8.04743\end{array}$ & $\begin{array}{l}\text { Mean }= \\
62.3318\end{array}$ \\
\hline \multirow[t]{3}{*}{$\begin{array}{l}\text { Scale }= \\
4.49172\end{array}$} & $\begin{array}{c}\text { Shape = } \\
0.0495829\end{array}$ & $\begin{array}{c}\text { Standard } \\
\text { deviation = } \\
6.09377\end{array}$ & $\begin{array}{l}\text { Scale }= \\
65.4393\end{array}$ & $\begin{array}{c}\begin{array}{c}\text { Standard } \\
\text { deviation } \\
= \\
6.50424\end{array} \\
\end{array}$ \\
\hline & & $\begin{array}{c}\text { Log scale: } \\
\text { mean }= \\
4.12763\end{array}$ & & \\
\hline & & $\begin{array}{l}\text { Log scale: } \\
\text { std. dev. }= \\
0.0975392\end{array}$ & & \\
\hline
\end{tabular}

Analysis in table (Tab. 2) shows the results of fitting 5 distributions to the data on whole eye duration. The estimated parameters of the fitted distributions are shown above

\subsection{Goodness-of-Fit Tests for whole eye duration}

Tab. 3: Kolmogorov-Smirnov Test

\begin{tabular}{|c|c|c|c|c|c|}
\hline & 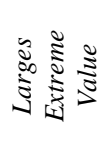 & 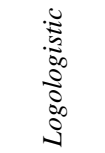 & 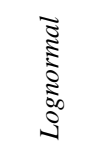 & 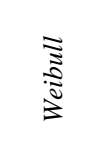 & $\begin{array}{l}\bar{\Xi} \\
\text { हे } \\
z\end{array}$ \\
\hline DPLUS & 0.0876279 & 0.0814483 & 0.131888 & 0.21272 & 0.155656 \\
\hline DMINUS & 0.104243 & 0.0911314 & 0.088552 & 0.191852 & 0.102562 \\
\hline DN & 0.104243 & 0.0911314 & 0.131888 & 0.212727 & 0.155656 \\
\hline $\begin{array}{l}\text { P-Value } \\
\text { P- }\end{array}$ & 0.777486 & 0.893946 & 0.501194 & 0.0525548 & 0.288327 \\
\hline
\end{tabular}

Table (Tab. 3) shows the results of tests run to determine whether whole eye duration can be adequately modeled by various distributions. P-values less than 0.05 would indicate that whole eye duration does not come from the selected distribution with $95 \%$ confidence.

Histogra $\mathrm{m}$ for whole eye duration [sec]

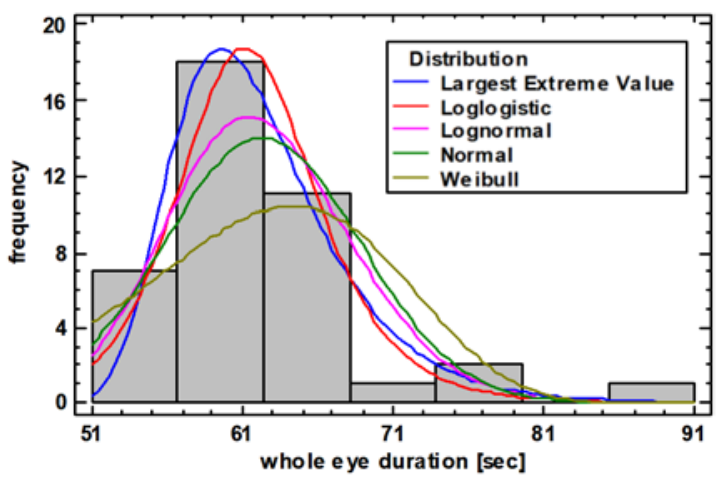

Figure 4: Histogram for whole eye duration

Graph in figure (Figure 4) shows a frequency histogram for whole eye duration. In this plot, 7 intervals have been formed ranging from a lower limit of 51.0 to an upper limit of 91.0. The number of data values in each interval has then been tabulated. The plot shows these frequencies. In addition, the probability density function for the fitted largest extreme value distribution has been superimposed on the histogram. If the distribution fits well, the top of the bars should be relatively close to the line. 
Qua ntile Plot

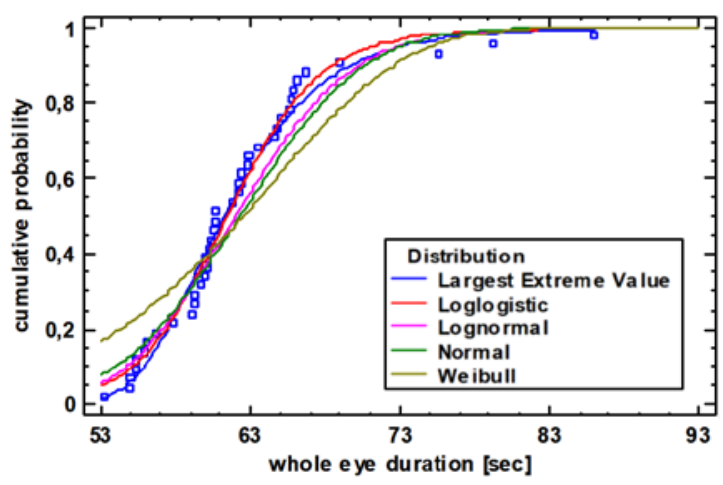

Figure 5: Quantile Plot

The quantile plot in figure (Figure 5) shows the empirical cumulative distribution function together with that of the fitted distribution. If the distribution fits the data well, the points should lie close to the curve.

Tab. 4: Comparison of Alternative Distributions

\begin{tabular}{|c|c|c|c|}
\hline Distribution & $\begin{array}{c}\text { Est. } \\
\text { Parameters }\end{array}$ & $\begin{array}{c}\text { Log } \\
\text { Likelihood }\end{array}$ & KS D \\
\hline $\begin{array}{c}\text { Largest } \\
\text { Extreme } \\
\text { Value }\end{array}$ & 2 & -124.126 & 0.104243 \\
\hline Loglogistic & 2 & -125.966 & 0.0911314 \\
\hline Laplace & 2 & -126.356 & 0.122156 \\
\hline Logistic & 2 & -127.588 & 0.0935 \\
\hline Lognormal & 2 & -128.263 & 0.131888 \\
\hline $\begin{array}{c}\text { Inverse } \\
\text { Gaussian }\end{array}$ & 2 & -128.289 & 0.130251 \\
\hline $\begin{array}{c}\text { Birnbaum- } \\
\text { Saunders }\end{array}$ & 2 & -128.293 & 0.130268 \\
\hline Gamma & 2 & -129.143 & 0.137018 \\
\hline Normal & 2 & -131.156 & 0.155656 \\
\hline Weibull & 2 & -138.91 & 0.212727 \\
\hline Uniform & 2 & -139.751 & 0.489183 \\
\hline $\begin{array}{c}\text { Smallest } \\
\text { Extreme } \\
\text { Value }\end{array}$ & 2 & -143.643 & 0.23873 \\
\hline Exponential & 1 & -205.299 & 0.573872 \\
\hline Pareto & 1 & -261.813 & 0.618123 \\
\hline
\end{tabular}

Table (Tab. 4) above compares the goodness-of-fit when various distributions are fit to whole eye duration. According to the log likelihood statistic, the best fitting distribution is the largest extreme value distribution

\section{Discussion}

The result shows that the manual production of glass eyes is should not be described by the normal probability distribution. The other probability distribution should be chosen to use capacity planning or simulation of the production system. Based on the Kolmogorov-Smirnov test of goodness of fit, a Loglogistic distribution with a P-Value of 0.893946 looks like the best distribution to describe the probability of duration of glass eye production. The second best-fitted result is with PValue 0.777486 Largest Extreme Value distribution. By comparing distribution by Log Likelihood statistic, the best fitting is the Larges Extreme Value distribution. One of these (Larges Extreme Value and Loglogistic) distributions should be chosen to represent this process. Then a generator of random numbers can be used to simulate the duration of glass eye processing.

An example of uncertain activity duration is modeled in [7], where the fuzzy number and discrete-event simulation are used.
The modeling of the simulation of the tablet coating, granulation, and nano-milling processes are discussed in [4], where probability distributions are just assumed. The goodness of fit method could search for the most fitting distributions for each process segment. A different approach for fitting probability distribution is introduced [8].

In [9] analytical, and Monte Carlo simulation approaches to evaluate probability distributions of interruption duration indices are described. In [1] well-fitted probability distributions of operation durations are used for capacity planning with a positive result.

\section{Conclusion}

A capacity or production planning can be calculated wrongly by incorrectly identifying the probability of time duration of operations in the production system. This can also be seen by using of wrong probability distribution in production system simulation. These wrong applications could lead to more significant mistakes and related costs. That is why a proper determination and verification of probability distribution of planned operation should be done. The approach to determining the probability distribution by using tests of goodness of fit was presented above.

\section{Literature:}

1. Lepsik P. DYNAMICAL MODEL OF CAPACITIVE PLANNING. Acta Technica Corviniensis - Bulletin of Engineering. 2010;3(1):19-24.

2. Zhang Z, Wang X, Wang X, Cui F, Cheng H. A simulationbased approach for plant layout design and production planning. J Ambient Intell Human Comput. 2019 Mar;10(3):1217-1230.

3. Rosova A, Behun M, Khouri S, Cehlar M, Ferencz V, Sofranko M. Case study: the simulation modeling to improve the efficiency and performance of production process. Wireless Netw [Internet]. 2020 May 5 [cited 2021 Oct 2]; Available from: https://link.springer.com/10.1007/s11276-020-02341-z

4. Papavasileiou V, Koulouris A, Siletti C, Petrides D. Optimize Manufacturing of Pharmaceutical Products with Process Simulation and Production Scheduling Tools. Chemical Engineering Research and Design. 2007 Jan;85(7):1086-1097. 5. Mun J. Advanced analytical models: over 800 models and 300 applications from the Basel II Accord to Wall Street and beyond. Hoboken, N.J: Wiley; 2008. 1013 p. (Wiley finance series).

6. Manolopoulos Y. Probability distributions for seek time evaluation. Information Sciences. 1992 Mar;60(1-2):29-40.

7. Zhang $\mathrm{H}$, Tam CM, Li H. Modeling uncertain activity duration by fuzzy number and discrete-event simulation. European Journal of Operational Research. 2005 Aug;164(3):715-729.

8. Thummler A, Buchholz P, Telek M. A Novel Approach for Fitting Probability Distributions to Real Trace Data with the EM Algorithm. In: 2005 International Conference on Dependable Systems and Networks (DSN'05) [Internet]. Yokohama, Japan: IEEE; 2005 [cited 2021 Oct 2]. p. 712-721. Available from: http://ieeexplore.ieee.org/document/1467845/

9. LeitedaSilva AM, Schmitt WF, Cassula AM, Sacramento CE. Analytical and Monte Carlo Approaches to Evaluate Probability Distributions of Interruption Duration. IEEE Trans Power Syst. 2005 Aug;20(3):1341-1348.

Primary Paper Section: J

Secondary Paper Section: JP, JS 